\title{
Early childhood and adolescent risk factors for psychotic depression in a general population birth cohort sample
}

\author{
Miika Nietola ${ }^{1} \cdot$ Hanna Huovinen ${ }^{2} \cdot$ Anni Heiskala $^{2} \cdot$ Tanja Nordström $^{2,3,4} \cdot$ Jouko Miettunen $^{2,3} \cdot$ Jyrki Korkeila $^{5}$. \\ Erika Jääskeläinen ${ }^{2,3,6}$
}

Received: 26 May 2019 / Accepted: 3 February 2020 / Published online: 13 February 2020

(c) The Author(s) 2020

\begin{abstract}
Background and purpose In the group of severe mental disorders, psychotic depression (PD) is essentially under-researched. Knowledge about the risk factors is scarce and this applies especially to early risk factors. Our aim was to study early childhood and adolescent risk factors of PD in a representative birth cohort sample with a follow-up of up to 50 years.

Methods The study was carried out using the Northern Finland Birth Cohort 1966 (NFBC 1966). We used non-psychotic depression (NPD) ( $n=746)$, schizophrenia (SZ) $(n=195)$, psychotic bipolar disorder (PBD) $(n=27)$, other psychoses (PNOS) $(n=136)$ and healthy controls (HC) $(n=8200)$ as comparison groups for PD $(n=58)$. We analysed several potential early risk factors from time of birth until the age of 16 years.

Results The main finding was that parents' psychiatric illness [HR 3.59 (1.84-7.04)] was a risk factor and a high sports grade in school was a protective factor [HR $0.29(0.11-0.73)$ ] for PD also after adjusting for covariates in the multivariate Cox regression model. Parental psychotic illness was an especially strong risk factor for PD. The PD subjects had a parent with psychiatric illness significantly more often $(p<0.05)$ than NPD subjects. Differences between PD and other disorder groups were otherwise small.

Conclusions A low sports grade in school may be a risk factor for PD. Psychiatric illnesses, especially psychoses, are common in the parents of PD subjects. A surprisingly low number of statistically significant risk factors may have resulted from the size of the PD sample and the underlying heterogeneity of the etiology of PD.
\end{abstract}

Keywords Psychotic depression $\cdot$ Risk factors $\cdot$ Epidemiology $\cdot$ Birth cohort $\cdot$ Psychosis

Electronic supplementary material The online version of this article (https://doi.org/10.1007/s00127-020-01835-7) contains supplementary material, which is available to authorized users.

Miika Nietola

mtniet@utu.fi

1 Psychiatric Department, University of Turku and the Hospital District of Southwest Finland, Kunnallissairaalantie 20, Building 9, 3. Floor, 20700 Turku, Finland

2 Center for Life Course Health Research, University of Oulu, Oulu, Finland

3 Medical Research Center Oulu, Oulu University Hospital and University of Oulu, Oulu, Finland

4 Infrastructure for Population Studies, Faculty of Medicine, University of Oulu, Oulu, Finland

5 Psychiatric Department, University of Turku and Satakunta Hospital District, Turku, Finland

6 Department of Psychiatry, Oulu University Hospital, Oulu, Finland

\section{Introduction}

Psychotic depression (PD) is a severe and under-researched disorder with a mostly similar clinical course than psychotic bipolar disorder (PBD), worse than in non-psychotic depression (NPD), but better than in schizophrenia (SZ) [1,2]. The large diagnostic conversion from PD to other diagnoses and the difficulty of properly identifying patients with PD present challenges to both clinical practice and research, and altogether our understanding of the relationship between PD and other psychotic and depressive illness is far from sufficient [3]. Supporting the validity of a separate diagnostic entity of PD, psychotic symptoms seem to occur with a high probability in recurrent depressive episodes in PD [4].

To understand the etiology of PD, and possible differences in comparison to other affective and psychotic illnesses, we need to know more about the risk factors. Very few studies have been conducted to discover the 
risk factors of psychotic depression, and especially early life risk factors [2]. There is only one previous Danish register-based study with a follow-up starting from birth. In their study the PD subjects did not differ from NPD or healthy control (HC) subjects regarding birth weight and gestational age. There was a trend in PD that low maternal age and high paternal age served as risk factors [5].

PD patients have been found to suffer more often from childhood traumatic events than NPD patients [6]; however, another study did not find this difference [7]. In the ÆSOP-study in the UK, childhood adversity was associated with PD. The same study found more neurological soft signs in PD patients than in control subjects without a psychotic illness [8].

Concerning other factors, the ethnicity of PD patients has in several studies been more often non-Caucasian [2]. Also, rural residence has been more common among PD patients than NPD patients [9]. Loss of a relative, and especially the loss of the mother, seems to function as risk factor for PD [5].

Parental mental illness is a known risk factor for a variety of different psychiatric disorders [10]. For PD, there are studies showing more family history of mental illness in general $[8,11]$ and a larger amount of parental mental illness in PD than NPD [5], but there are also contradictory results $[12,13]$. There is some evidence that bipolar disorder $[5,14]$ and psychosis $[8,15]$ are more common in the families of PD. Family history of depression has not been found to be significantly more common in PD vs. NPD, possibly due to small sample sizes [16-18].

Altogether, the PD risk factor profile has been shown to overlap highly with NPD [5], and to have many more similarities with SZ than with PBD [8]. This conflicts with outcome studies that posit PD as near PBD and separate it from SZ and NPD. Most studies to date have utilized cross-sectional, retrospectively collected information and early risk factors are mostly unknown.

\section{Aims of the study}

Our aim in this study was to analyse several early childhood and adolescent risk factors of PD in the prospectively collected, general population based Northern Finland Birth Cohort 1966 (NFBC 1966). One purpose was to discover potential differences and similarities in risk factor profiles between disorder groups, comparing PD to NPD, SZ, PBD, PNOS and HC.

\section{Methods}

\section{Sample}

Our data came from the NFBC 1966 [19]. The cohort utilizes nationwide registers of hospitalization and outpatient care in Finland in addition to questionnaires and clinical examination data. Psychiatric diagnoses of the NFBC 1966 members were gained from several national registers: Care Register for Health Care was used to acquire diagnoses of all general and psychiatric hospitalizations from birth until the end of 2016. Outpatient diagnoses came from the Finnish outpatient register (specialized care 1998-2016; primary care 2011-2016). Register information about drug reimbursement (until 2005), sick days (until 1999) and disability pensions (until 2015), were also used to gather the lifetime diagnoses of individuals in the cohort.

All the study groups were formed according to lifetime diagnosis, which was defined by the hierarchically highest diagnosis in the data. The hierarchical order starting from the top was SZ ( $n=195)$, PBD $(n=27)$, PD $(n=58)$, PNOS $(n=136)$, NPD $(n=746)$, and HC $(n=8200)$. The hierarchical system is described in more detail elsewhere [20]. The diagnoses of each study group are presented in Table 1 . In the PD group, all lifetime diagnoses were manually checked. In a previous study of the cohort by our group [20], there were 55 PD subjects until the end of 2013, 2 of whom were converted to schizophrenia or bipolar disorder afterwards.

Table 1 Diagnostic categories based on ICD 8-10 used in the current study

\begin{tabular}{llll}
\hline & ICD-8 & ICD-9 & ICD-10 \\
\hline Psychotic depression (PD) & 2960,2980 & $2961 \mathrm{E}$ & F32.3, F33.3 \\
Non-psychotic depression (NPD) & 3004,7902 & 3004 & F32.0-F32.2, F32.8-F33.2, \\
& & & F33.4-F33.9, F34.1, \\
& & F38.10 & F20, F25 \\
Schizophrenia (SZ) & $295,2954,2957$ & $2962 \mathrm{E}, 2963 \mathrm{E}, 2964 \mathrm{E}, 2967$ & F30.2, F31.2, F31.5 \\
Psychotic bipolar disorder (PBD) & $2961-2969$ & $297,2988,2989$ & F22, F23, F24, F28, F29 \\
Other psychoses (PNOS) & 297,298 (except 2980), 299 & No psychiatric diagnoses & No psychiatric diagnoses \\
Healthy controls (HC) & No psychiatric diagnoses & &
\end{tabular}


There were also five new PD cases, resulting in the current PD sample size of 58. The HC group subjects did not have any lifetime psychiatric diagnoses, which means we excluded subjects with disorders other than those of the comparison groups. Also, cohort participants who died or moved to another country before the age of 16 years were excluded.

\section{Risk factors}

Since there is very little research on the risk factors of PD, we performed an explorative analysis of risk factors that have been studied in earlier studies of SZ, PBD or NPD. The risk factors were grouped into the following categories: psychiatric and somatic illness of the parents, psychosocial risk factors, biological risk factors, school performance and risk of psychotic depression and other mental disorders and health-related risk factors at age 14 years.

\section{Psychiatric and somatic illness of the parents}

Data concerning the psychiatric and somatic illness of the parents was gathered from the same registers, listed above, as the study subjects. Regarding somatic illness, we analysed long hospitalizations ( $\geq 30$ days) of both parents separately as potential risk factors [21]. Only hospitalizations that took place before the end of 1982, i.e. the year when the study subject reached the age of 16 years, were taken into account. We chose this variable because separation from and possible fear of loss of the parent represents a traumatic event for the child. Childhood traumatic events are known to be associated with many psychiatric disorders later in life [22]. Psychiatric illness (any psychiatric illness, psychosis, schizophrenia, depression, bipolar disorder and alcohol use disorder) of the parents before the study subject reached the age of 16 years was analysed using the same register information as with study group subjects.

\section{Psychosocial risk factors}

We divided psychosocial risk factors into risk factors during birth and risk factors at age 14 years. The same questionnaire from 1965 to 1966 for biological risk factors was used for the risk factors during birth: urbanicity, mother's education, social class in 1966 (determined by father's occupation), mother's antenatal mood [23] and unwantedness of pregnancy [24]. In 1980, at the age of 14 years, the cohort members filled out a questionnaire, which provided information about the subjects' family type, social class in 1980 (determined by father's occupation), moving hometown in 1966-1980 and mother's work status. In the questionnaire, participants were also asked whether one or several of their siblings were previously deceased and to write down the number. The deceased siblings variable is based on this question and has two categories: yes/no. This variable is also an indicator of a traumatic childhood event (see above for psychiatric and somatic illness of the parents).

\section{Biological risk factors}

Information about birth weight, gestational age, birth weight/gestational age, parity, paternal and maternal age, mother's antenatal smoking [23] and perinatal complications [25] were collected in a questionnaire that was filled in by an interviewing nurse at the antenatal clinic and at birth in 1965-1966.

Motor development of all children in Finland is regularly followed by nurses and doctors in Finnish welfare clinics as a routine procedure; the child is observed and the parents interviewed. The age when child achieves a particular milestone is written on a welfare card and we used the information on these cards about motor development. We selected the ages when the child learns to walk and stand without support as indicators of early motor development [21].

\section{School performance and risk of psychotic depression and other mental disorders}

The register information from the National Board of Education was combined with the postal questionnaire from 1980 to confirm the school level of the persons at the age of 14 years. Data about the study subjects' school grades at the age of 16 years were obtained in 1982 from the Finnish national application system for upper secondary education register. The National Board of Education defines the criteria for school grades and they are same in all Finnish schools [26]. Pupils were graded by their teachers at the age of 16 years. School grade categories were as follows: 4-6 (4.00-6.99); 7-8 (7.00-8.99); 9-10 (9.00-10.00) [27].

\section{Health-related risk factors at age 14 years}

The same questionnaire from 1980 that was used to measure psychosocial risk factors at age 14 years was used to gather information about subjects' health behaviour (alcohol and smoking consumption, frequency of sport hobbies and BMI).

\section{Missing data}

Since most of the data were acquired through questionnaires, we had a varying level of missing data, from 0 to $32.8 \%$, in different variables with the average proportion of missing data being $9.2 \%$ in the PD group. The highest amount of missing data was in the variable standing without support $(32.8 \%)$. 


\section{Statistical analyses}

Contingency tables were first applied to analyse frequency distribution of the variables in different diagnostic groups. We used Cox proportional-hazards model to calculate the hazard ratio for each risk factor separately comparing PD to HC. The end point in the Cox regression analysis was illness onset, death, moving abroad or the end of 2016. We did a multivariate Cox regression model in which we chose those variables that had a low $p$ value $(p<0.1)$ in one or more variable categories in the univariate analysis comparing PD to HC. If there were several parental mental illness variables with a low $p$ value, we chose the one with the lowest $p$ value. The multivariate model included four variables (Table 2). For comparisons between different disorder groups, we used Pearson's Chi-square test or Fisher's exact test. We used SPSS version 25 for statistical analyses (https ://www.ibm.com/analytics/spss-statistics-software).

\section{Results}

\section{Characteristics of the sample}

There were 58 subjects with a hierarchical lifetime diagnosis of PD at the end of 2016. Lifetime prevalence of PD was $0.5 \%$. The proportion of females was $60.3 \%$. The comparison groups were as follows: NPD $(n=746)$, SZ $(n=195)$, PBD $(n=27)$, PNOS $(n=136)$ and HC $(n=8200)$. Cumulative incidences of the groups are presented in Fig. 1.

Table 2 Multivariate Cox regression model for risk factors of PD

\begin{tabular}{ll}
\hline Variables & HR for PD (95\% CI) \\
\hline Parent's any psychiatric illness (either parent or both) \\
No & Ref \\
Yes & $3.59(1.84-7.04)$ \\
Family type in 1980 & \\
Two-parent family & Ref \\
Single-parent family or no parents & $1.59(0.79-3.19)$ \\
Grade of physical education in 1982 & \\
$4-6$ & $1.03(0.37-2.89)$ \\
$7-8$ & Ref \\
$9-10$ & $0.29(0.11-0.73)$ \\
Unwantedness of pregnancy & \\
Wanted or mistimed & Ref \\
Unwanted & $1.24(0.55-2.79)$ \\
\hline
\end{tabular}

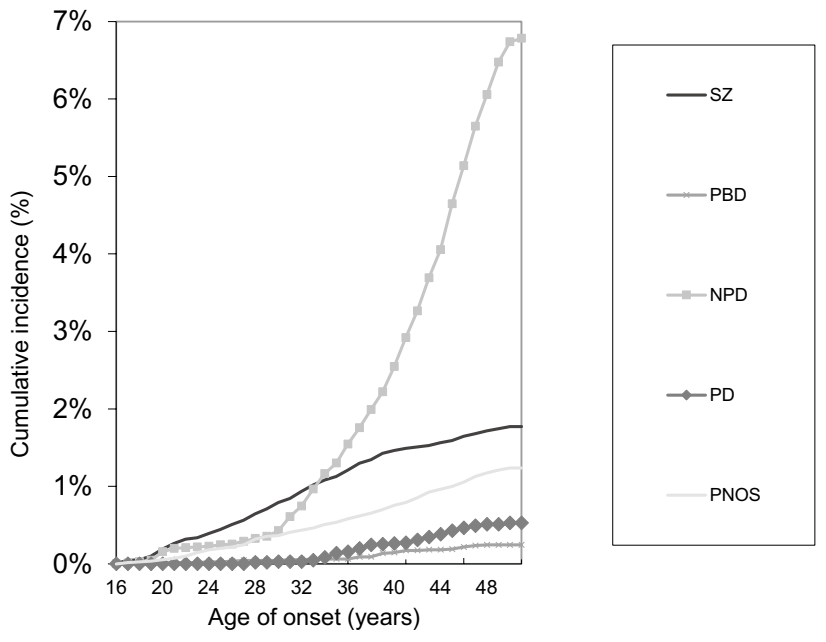

Fig. 1 Cumulative incidence of psychotic depression (PD), non-psychotic depression (NPD), schizophrenia (SZ), psychotic bipolar disorder (PBD) and other psychoses (PNOS)

\section{Univariate analysis of PD risk factors when compared to HC}

Compared to HC, PD subjects were significantly more likely to have a parent/parents with any psychiatric illness (HR 3.63 (1.99-6.62)), any psychosis (HR 3.89 (1.41-10.73) and schizophrenia (HR 4.60 (1.44-14.71)), but not a parent with depression or bipolar disorder. Results regarding parental mental illness are presented in the Supplementary Table S1.

Lower frequency of sport hobbies (at most once a fortnight: HR 2.03 (1.00-4.12) at the age of 14 years was a significant risk factor for $\mathrm{PD}$, while a higher school sport grade was a protective factor (HR $0.37(0.16-0.82)$ ). Another significant finding was that living in a single-parent family or without parents at the age of 14 years increased the risk for the development of PD (HR 2.12 (1.11-4.08). (Supplementary Tables S2 and S4-S5).

Most of the findings remained nonsignificant. None of the psychosocial risk factors during birth showed significant risk. Also, the amount of hospitalizations of the parents of study subjects, due to somatic illness, were few in number $(n=3)$ and the difference nonsignificant. (Supplementary Tables S1-S2).

Birth parameters (birth weight, gestational age, birth weight/gestational age) in the PD group had more deviation from the normal range than in the $\mathrm{HC}$ group. There were still no statistically significant differences between the PD and $\mathrm{HC}$ groups. Findings regarding motor development and maternal and paternal age were also nonsignificant. (Supplementary Table S3).

Most variables at age 14 years showed no significant risk. School performance in the PD group was worse in all studied variables, but differences did not reach statistical 
significance. Alcohol and smoking habits showed no distinctive characteristics in comparison to the HC group (Supplementary Tables S2, S4 and S5).

\section{Multivariate Cox regression model}

We included, in the multivariate model, the variables that had a $p$ value under 0.1 in one or more categories in the univariate Cox regression analysis when PD was compared to HC. Regarding parental mental illness, there were several variables with $p<0.1$, and we selected any parental mental illness, which had the strongest effect. Out of two variables describing physical activity, we selected grade of physical education, also due to the stronger effect. We excluded mean grade of non-theoretical school subjects, since it included grade of physical education. After this, four variables were included in the multivariate model (Table 2). After adjusting for covariates in the multivariate model, only any parental mental illness (HR 3.59 (1.84-7.04)) remained a strong risk factor and high grade of physical education (HR 0.29 $(0.11-0.73))$ a protective factor of PD.

\section{Comparison to other disorder groups}

We compared PD risk factors to all other disorder groups. Psychiatric illness among parents was significantly more common in the PD group when compared to the NPD group $(p=0.031)$. Other group comparisons regarding parental mental illness remained nonsignificant. Otherwise, there were only a few significant differences between disorder groups. The proportion of subjects at lower school level was smaller in PD $(5.4 \%)(p=0.031)$ than in SZ $(17.4 \%)$. Also, PD subjects more often $(14.6 \%)(p=0.032)$ had a deceased sibling than $\mathrm{SZ}$ subjects (4.8\%).

\section{Discussion}

We analysed several early life risk factors of PD for the first time in a prospective study. The $0.5 \%$ prevalence rate of PD in the sample was in line with previous findings [2, 28]. A significant finding in this study was a high prevalence of mental illness in the families of PD subjects, and higher than that of those with NPD. Otherwise, there were only few significant differences between PD and other disorder groups. PD subjects had more often a deceased sibling and were less often at a lower school level than schizophrenia subjects. We also found PD subjects, compared to HC, to have lower sports grades and a lower frequency of sport hobbies in adolescence, and they more often grew up in a single-parent family.

The proportion of psychosis and schizophrenia, but not depression or bipolar disorder, was found to be significantly more common among parents in PD compared to the $\mathrm{HC}$ group. Findings concerning parental mental illness in general and psychosis are in line with previous populationrepresentative research [8], but our finding of no bipolar disorder among parents of the study subjects was surprising and conflicting [5]. The fact that in our study non-psychotic depression of the parent was not more common among PD subjects than among any other group, including HC group, is likely due to the small sample size, the unavailability of outpatient diagnoses before 1998 and changing diagnostic practices through the decades (see "Strengths and limitations" section).

Both lower school sports grades and reported frequency of sport hobbies may reflect low physical activity. After adjusting for covariates in the multivariate cox regression model, a higher sports grade remained a significant protective factor for PD compared to HC. Previously, people with major depression are known to have lower levels of physical activity [29] and higher levels of physical activity are known to prevent the development of depression [30]. Also, low levels of physical activity in childhood and adolescence increase the risk of non-affective psychosis later in life, possibly contributed to by deviant motor development [31]. However, we did not find significant differences of motor development in PD, which was consistent with previous research limiting deviant motor development to non-affective psychoses [32]. It is also important to notice that sports grade is influenced by a variety of factors other than physical activity such as physical health, motivation, interpersonal capabilities and genetic factors.

It has been argued that the role of physical activity should be increased in the treatment of depression [33] and severe mental illness in general [34]. Our results support the view that low physical activity is a transdiagnostic marker for later illness across the spectrum of mental illness and a relevant target for prevention and treatment.

Single parenthood has been associated with multiple negative mental health outcomes [35], but many factors associated with single parenthood contribute significantly to this effect [36]. In line with these findings, in our sample, single parenthood or living without parents was a significant risk factor for PD compared to $\mathrm{HC}$ in the univariate analysis, but not after adjusting for covariates in the multivariate model.

Our results, with a majority of nonsignificant findings, are also worth considering more closely. It is possible that internal heterogeneity of the diagnostic category of PD partly causes the lack of findings. It is already known that there are significant clinical differences between psychotic depression that has its onset in early adulthood versus psychotic depression in old age [2, 37]. In addition, major depression in general is a highly heterogeneous entity [38]. There might also be significant internal heterogeneity due to different aetiologies in the same age group of PD patients, contributing to 
the lack of significant risk factors. More long-term follow-up studies focusing on this subject would be likely to have much to offer for the understanding and individualized treatment of PD patients.

\section{Strengths and limitations}

Our data come from a representative birth cohort, with a prospective follow-up from mid-pregnancy 1965-1966 until 2016, approximately 50 years in total. Also, the utilization of national registers gives us a reliable estimate of the treated psychiatric illness both in the cohort subjects and in their families. The method of hierarchical lifetime diagnosis gave us the possibility to examine distinctly those PD patients whose diagnosis did not convert to other psychotic illness by the age of 50 years. A major strength was also that we were able to study many early life variables in the same study. There was some, but not an extensive amount of missing data, the average proportion in the PD group being $9.2 \%$.

The validity of register diagnoses is unfortunately not optimal. However, we believe that the long follow-up (up to 50 years) and our ability to obtain diagnoses since birth for hospitalizations and since 1998 for specialized outpatient care increase this validity significantly. After excluding those subjects who had also been diagnosed with a schizophrenia spectrum disorder, delusional disorder or bipolar disorder during their lifetime, our sample included 58 subjects whose most severe lifetime diagnosis was PD. If the PD diagnosis would have been wrong and the patient was suffering from another severe psychotic disorder, the patient would have likely been diagnosed with that particular disorder later on. The other possibility of misdiagnosis is overdiagnosis, in which the patient was diagnosed with PD when the patient was in fact suffering from non-psychotic depression. The likelihood of this, in our opinion, is low, since the psychotic symptoms are more likely to be missed than overdiagnosed in depression [39].

One limitation in the study was the use of changing diagnostic systems (ICD 8-10) over the decades. We know that the prevalence of affective psychoses has increased in Northern Finland [40], possibly contributed to by a change in diagnostic practices. This especially concerns our finding of only a few cases of depression or bipolar disorder in the parents of PD subjects. Diagnostic practices in Finland have likely shifted to a more prevalent diagnosis of depression [41], whereas the use of other diagnoses was more common during ICD-8 and ICD-9. This may have led to an underestimation of the prevalence of depression or bipolar disorder among the parents of PD patients.

The sample size of PBD was unfortunately low $(n=27)$, reducing the reliability of the results concerning this diagnostic group. However, we wanted to include this important comparison group since this is the first prospective study to examine the early risk factors of PD. Also, PBD has not been extensively studied separately from non-psychotic bipolar disorder.

Also, the unavailable information of outpatient care diagnoses before the year 1998 means that some early-onset cases with milder symptoms are likely to have been missed. This is not a concern in the PD group with a very high hospitalization rate [20], but it is likely that in our study the NPD group represents a more severe portion of illness cases.

Because of lack of data, we were not able to analyse the effects of certain potential risk factors. Cannabis use, migration and the majority of childhood traumatic events are examples of such risk factors that were not possible to study here. In addition, we studied only risk factors in early childhood and adolescence, while many factors later in life may increase the risk of PD.

Our study also has a limitation regarding the age of the sample, since we were not able to include subjects who were diagnosed with PD after the age of 50 years. Therefore, our results should not be interpreted to be representative of late-onset PD, for which other factors might cause predispositions.

We consider our sample size of 58 in the PD group to be relatively small, but sufficient to discover potential robust risk factors. However, it is still possible that smaller effects may have gone unnoticed. Altogether, our findings in this explorative study are to be regarded as preliminary, as no comprehensive adjustment for confounding variables was performed. Also, we did multiple comparisons, which means that chance findings are possible.

\section{Conclusions}

Low school sports grade in adolescence and familial mental illness were common factors in PD in our study. The PD risk factor profile was similar to that of other mental illness in most variables. A small number of significant risk factors may point to underlying heterogeneity. Research on the risk factors of PD should also be carried out in other samples to reduce the gap in knowledge.

Acknowledgements Open access funding provided by University of Turku (UTU) including Turku University Central Hospital. This work was funded by Turku University Foundation (Grant Number: 10-2305).

Conflict of interest The authors declare that they have no conflict of interest.

Ethical statement This study has been approved by the relevant and appropriate ethics committee and, therefore, has been performed in accordance with the ethical standards laid down in the 1964 Declaration of Helsinki and its later amendments. 
Open Access This article is licensed under a Creative Commons Attribution 4.0 International License, which permits use, sharing, adaptation, distribution and reproduction in any medium or format, as long as you give appropriate credit to the original author(s) and the source, provide a link to the Creative Commons licence, and indicate if changes were made. The images or other third party material in this article are included in the article's Creative Commons licence, unless indicated otherwise in a credit line to the material. If material is not included in the article's Creative Commons licence and your intended use is not permitted by statutory regulation or exceeds the permitted use, you will need to obtain permission directly from the copyright holder. To view a copy of this licence, visit http://creativecommons.org/licenses/by/4.0/.

\section{References}

1. Heslin M, Lappin JM, Donoghue K, Lomas B, Reininghaus U, Onyejiaka A, Croudace T, Jones PB, Murray RM, Fearon P, Doody GA, Dazzan P, Craig TJ, Morgan C (2016) Ten-year outcomes in first episode psychotic major depression patients compared with schizophrenia and bipolar patients. Schizophr Res 176(2-3):417-422

2. Jääskeläinen E, Juola T, Korpela H, Lehtiniemi H, Nietola M, Korkeila J, Miettunen J (2018) Epidemiology of psychotic depression - systematic review and meta-analysis. Psychol Med 48(6):905-918

3. Heslin M, Young AH (2018) Psychotic major depression: challenges in clinical practice and research. Br J Psychiatry 212(3):131-133

4. Nelson JC, Bickford D, Delucchi K, Fiedorowicz JG, Coryell WH (2018) Risk of Psychosis in Recurrent Episodes of Psychotic and Nonpsychotic Major Depressive Disorder: A Systematic Review and Meta-Analysis. Am J Psychiatry 175(9):897-904

5. Ostergaard SD, Waltoft BL, Mortensen PB, Mors O (2013) Environmental and familial risk factors for psychotic and non-psychotic severe depression. J Affect Disord 147(1-3):232-240

6. Gaudiano BA, Zimmerman M (2010) The relationship between childhood trauma history and the psychotic subtype of major depression. Acta Psychiatr Scand 121(6):462-470

7. Gaudiano BA, Weinstock LM, Epstein-Lubow G, Uebelacker LA, Miller IW (2016) Clinical characteristics and medication use patterns among hospitalized patients admitted with psychotic vs nonpsychotic major depressive disorder. Ann Clin Psychiatry 28(1):56-63

8. Heslin M, Desai R, Lappin JM, Donoghue K, Lomas B, Reininghaus U, Onyejiaka A, Croudace T, Jones PB, Murray RM, Fearon P, Doody GA, Dazzan P, Fisher HL, Demjaha A, Craig T, Morgan C (2016) Biological and psychosocial risk factors for psychotic major depression. Soc Psychiatry Psychiatr Epidemiol 51(2):233-245

9. Ihezue UH (1985) Observations and comments on the psychosocial determinants of depressive illness among Nigerian adults. $\mathbf{J}$ Natl Med Assoc 77(9):729-733

10. Dean K, Stevens H, Mortensen PB, Murray RM, Walsh E, Pedersen CB (2010) Full spectrum of psychiatric outcomes among offspring with parental history of mental disorder. Arch Gen Psychiatry 67(8):822-829

11. Okulate GT, Oladapo HT, Osibogun A (2001) Comparison of three subtypes of depression. Niger Postgrad Med J 8(1):41-45

12. Frangos E, Athanassenas G, Tsitourides S, Psilolignos P, Katsanou N (1983) Psychotic depressive disorder. A separate entity? J Affect Disord 5(3):259-265

13. Nakamura K, Iga J, Matsumoto N, Ohmori T (2015) Risk of bipolar disorder and psychotic features in patients initially hospitalised with severe depression. Acta Neuropsychiatr 27(2):113-118
14. Maj M, Pirozzi R, Magliano L, Fiorillo A, Bartoli L (2007) Phenomenology and prognostic significance of delusions in major depressive disorder: a 10-year prospective follow-up study. J Clin Psychiatry 68(9):1411-1417

15. Buoli M, Caldiroli A, Altamura AC (2013) Psychotic versus nonpsychotic major depressive disorder: a comparative naturalistic study. Asian J Psychiatr 6(4):333-337

16. Parker G, Hadzi-Pavlovic D, Hickie I, Mitchell P, Wilhelm K, Brodaty H, Boyce P, Eyers K, Pedic F (1991) Psychotic depression: a review and clinical experience. Aust N Z J Psychiatry 25(2):169-180

17. Simpson S, Baldwin RC, Jackson A, Burns A (1999) The differentiation of DSM-III-R psychotic depression in later life from nonpsychotic depression: comparisons of brain changes measured by multispectral analysis of magnetic resonance brain images, neuropsychological findings, and clinical features. Biol Psychiatry 45(2):193-204

18. Park SC, Lee HY, Sakong JK, Jun TY, Lee MS, Kim JM, Kim JB, Yim HW, Park YC (2014) Distinctive Clinical Correlates of Psychotic Major Depression: The CRESCEND Study. Psychiatry Investig 11(3):281-289

19. Jääskeläinen E, Haapea M, Rautio N, Juola P, Penttilä M, Nordström T, Rissanen I, Husa A, Keskinen E, Marttila R, Filatova S, Paaso T-M, Koivukangas J, Moilanen K, Isohanni M, Miettunen J (2015) Twenty years of schizophrenia research in the Northern Finland Birth Cohort 1966: A Systematic Review. Schizophr Res Treat 2015:524875

20. Nietola M, Heiskala A, Nordström T, Miettunen J, Korkeila J, Jääskeläinen E (2018) Clinical characteristics and outcomes of psychotic depression in the Northern Finland Birth Cohort 1966. Eur Psychiatry 53:23-30

21. Keskinen E, Marttila A, Marttila R, Jones PB, Murray GK, Moilanen K, Koivumaa-Honkanen $\mathrm{H}$, Mäki P, Isohanni M, Jääskeläinen E, Miettunen J (2015) Interaction between parental psychosis and early motor development and the risk of schizophrenia in a general population birth cohort. Eur Psychiatry 30(6):719-727

22. Kessler RC, Davis CG, Kendler KS (1997) Childhood adversity and adult psychiatric disorder in the US National Comorbidity Survey. Psychol Med 27(5):1101-1119

23. Keskinen E, Miettunen J, Koivumaa-Honkanen H, Mäki P, Isohanni M, Jääskeläinen E (2013) Interaction between parental psychosis and risk factors during pregnancy and birth for schizophrenia - the Northern Finland 1966 Birth Cohort study. Schizophr Res 145(1-3):56-62

24. Myhrman A, Rantakallio P, Isohanni M, Jones P, Partanen U (1996) Unwantedness of a pregnancy and schizophrenia in the child. Br J Psychiatry 169(5):637-640

25. Mäki P, Riekki T, Miettunen J, Isohanni M, Jones PB, Murray GK, Veijola J (2010) Schizophrenia in the offspring of antenatally depressed mothers in the northern Finland 1966 birth cohort: relationship to family history of psychosis. Am J Psychiatry 167(1):70-77

26. Isohanni I, Järvelin MR, Jones P, Jokelainen J, Isohanni M (1999) Can excellent school performance be a precursor of schizophrenia? A 28-year follow-up in the Northern Finland 1966 birth cohort. Acta Psychiatr Scand 100(1):17-26

27. Keskinen E, Marttila R, Koivumaa-Honkanen H, Moilanen K, Keinänen-Kiukaanniemi S, Timonen M, Isohanni M, McGrath J, Miettunen J, Jääskeläinen E (2018) Search for protective factors for psychosis - a population-based sample with special interest in unaffected individuals with parental psychosis. Early Interv Psychiatry 12(5):869-878

28. Perälä J, Suvisaari J, Saarni SI, Kuoppasalmi K, Isometsä E, Pirkola S, Partonen T, Tuulio-Henriksson A, Hintikka J, Kieseppä T, Härkänen T, Koskinen S, Lönnqvist J (2007) Lifetime 
prevalence of psychotic and bipolar I disorders in a general population. Arch Gen Psychiatry 64(1):19-28

29. Schuch F, Vancampfort D, Firth J, Rosenbaum S, Ward P, Reichert T, Bagatini NC, Bgeginski R, Stubbs B (2017) Physical activity and sedentary behavior in people with major depressive disorder: A systematic review and meta-analysis. J Affect Disord 210:139-150

30. Schuch FB, Vancampfort D, Firth J, Rosenbaum S, Ward PB, Silva ES, Hallgren M, Ponce De Leon A, Dunn AL, Deslandes AC, Fleck MP, Carvalho AF, Stubbs B (2018) Physical Activity and Incident Depression: A Meta-Analysis of Prospective Cohort Studies. Am J Psychiatry 175(7):631-648

31. Sormunen E, Saarinen MM, Salokangas RKR, Telama R, HutriKähönen N, Tammelin T, Viikari J, Raitakari O, Hietala J (2017) Effects of childhood and adolescence physical activity patterns on psychosis risk-a general population cohort study. NPJ Schizophr 3:5

32. Cannon M, Caspi A, Moffitt TE, Harrington H, Taylor A, Murray RM, Poulton R (2002) Evidence for early-childhood, pandevelopmental impairment specific to schizophreniform disorder: results from a longitudinal birth cohort. Arch Gen Psychiatry 59(5):449-456

33. Hallgren M, Stubbs B, Vancampfort D, Lundin A, Jääkallio P, Forsell Y (2017) Treatment guidelines for depression: Greater emphasis on physical activity is needed. Eur Psychiatry 40:1-3

34. Vancampfort D, Firth J, Schuch FB, Rosenbaum S, Mugisha J, Hallgren M, Probst M, Ward PB, Gaughran F, De Hert M, Carvalho AF, Stubbs B (2017) Sedentary behavior and physical activity levels in people with schizophrenia, bipolar disorder and major depressive disorder: a global systematic review and meta-analysis. World Psychiatry 16(3):308-315
35. Daryanani I, Hamilton JL, Abramson LY, Alloy LB (2016) Single Mother Parenting and Adolescent Psychopathology. J Abnorm Child Psychol 44(7):1411-1423

36. Fergusson DM, Boden JM, Horwood LJ (2007) Exposure to single parenthood in childhood and later mental health, educational, economic, and criminal behavior outcomes. Arch Gen Psychiatry 64(9):1089-1095

37. Gournellis R, Oulis P, Howard R (2014) Psychotic major depression in older people: a systematic review. Int J Geriatr Psychiatry 29(8):789-796

38. Lieblich SM, Castle DJ, Pantelis C, Hopwood M, Young AH, Everall IP (2015) High heterogeneity and low reliability in the diagnosis of major depression will impair the development of new drugs. BJPsych Open 1(2):e5-e7

39. Rothschild AJ, Winer J, Flint AJ, Mulsant BH, Whyte EM, Heo M, Fratoni S, Gabriele M, Kasapinovic S, Meyers BS, Study of Pharmacotherapy of Psychotic Depression (STOP-PD) Collaborative Study Group (2008) Missed diagnosis of psychotic depression at 4 academic medical centers. J Clin Psychiatry 69(8):1293-1296

40. Filatova S, Marttila R, Koivumaa-Honkanen H, Nordström T, Veijola J, Mäki P, Khandaker GM, Isohanni M, Jääskeläinen E, Moilanen K, Miettunen J (2017) A comparison of the cumulative incidence and early risk factors for psychotic disorder in young adults in the Northern Finland Birth Cohorts 1966 and 1986. Epidemiol Psychiatr Sci 26(3):314-324

41. Korkeila JA, Lehtinen V, Tuori T, Helenius H (1990s) Patterns of psychiatric hospital service use in Finland: a national register study of hospital discharges in the early 1990s. Soc Psychiatry Psychiatr Epidemiol 33(5):218-223 